\title{
Now, It Is Time to Consider Job Stress in the Field of Gastroenterology
}

\author{
Young Joo Yang and Gwang Ho Baik \\ Department of Internal Medicine, Hallym University College of Medicine, Chuncheon, Korea
}

See "Job Stress and Job Satisfaction among Health-Care Workers of Endoscopy Units in Korea" by Seung-Joo Nam, Hoon Jai Chun, Jeong Seop Moon, et al., on page 266-272.

In the last decade, rapid changes in medical practice, including rising demand for healthcare services, academic specialization, and increased responsibility for patients, has had a great influence on physicians' job stress and burnout, where the latter signifies a long term stress reaction characterized by a loss of enthusiasm for work, depersonalization, and a lack of a sense of personal accomplishment. ${ }^{1}$ Shanafelt et al. ${ }^{2}$ reported that $30 \%$ to $65 \%$ of United States physicians across medical specialties experienced at least one symptom of burnout and several studies have shown that there are high levels of job stress and burnout in surgery, oncology, and emergency medicine..$^{2-5}$ Moreover, previous studies have demonstrated that extreme job stress and burnout lead not only to negative personal effects for physicians including increased absenteeism, job turnover, early retirement, and mental well-being problems, but also an increased risk of medical errors, that contributes to adverse effects on the quality of patient care. ${ }^{6-10}$

Until now, there have been few investigations of job stress and burnout in the field of gastroenterology. Keswani et al. ${ }^{11}$

Received: April 29, 2016 Revised: May 11, 2016

Accepted: May 11, 2016

Correspondence: Gwang Ho Baik

Department of Internal Medicine, Hallym University Chuncheon Sacred Heart Hospital, Hallym University College of Medicine, 77 Sakju-ro, Chuncheon 24253, Korea

Tel: +82-33-240-5821, Fax: +82-33-241-8064, E-mail: baikgh@hallym.or.kr

(cc) This is an Open Access article distributed under the terms of the Creative Commons Attribution Non-Commercial License (http://creativecommons.org/ licenses/by-nc/3.0) which permits unrestricted non-commercial use, distribution, and reproduction in any medium, provided the original work is properly cited. showed that most gastroenterologists (GEs) in the United States experienced moderate levels of burnout and junior GE (those with 3 or fewer years of experience) had higher levels of stress related to endoscopic practice than senior GE regardless of interventional procedures. For nurses, Son and Yang $^{12}$ reported that endoscopic unit nurses in Korea suffered a great deal of stress, similar to what nurses in intensive care units experienced.

In this issue of Clinical Endoscopy, Nam et al. ${ }^{13}$ analyzed job stress levels by using the Korean occupational stress scale (KOSS) and assessing job satisfaction among 59 health-care providers working in teams in the endoscopy units of university-affiliated hospitals in Korea. They reported that nurses had significantly higher levels of job stress (48.92 \pm 7.97 ) compared to doctors $(42.59 \pm 6.37)$, and that the total job stress scores for the endoscopy unit workers (46.39 \pm 7.81$)$ were lower than those of a national sample of Korean workers (51.23 \pm 8.83$)$. Additionally, job stress was significantly associated with job demand, insufficient job control, and job insecurity in endoscopy units. ${ }^{13}$ Because previously reported investigations were performed according to occupation, and there was no data about job stress in the field of gastroenterology in Korea, this investigation has important meaning in that this is the first study evaluating job stress and job satisfaction of endoscopic unit team workers in actual clinical practice in Korea.

However, this study revealed several issues that we must consider. First, the method used to evaluate job stress in this study seems to be inadequate for assessing workers in endos- 
copy units. Because the KOSS score was designed to apply to all occupations in the general Korean population, it has difficulty reflecting the distinctive occupational environment of endoscopic unit workers, including emergency endoscopy, acquisition of new endoscopic skills, complexity of interventional procedures, and concerns about procedural complications. Therefore, an additional inventory specific to the field of gastroenterology, such as the GE stress inventory, is required. Second, the finding of the present study that there were significant differences in job stress and satisfaction according to job position should be interpreted cautiously. Because the KOSS focuses on analyzing factors related to job stress, it does not include personal characteristics, and we therefore could not evaluate actual response levels for job stress. Previous studies have demonstrated that multiple factors including demographic and life style characteristics such as age, sex, marital status, having a hobby, and regular exercise influence job stress. Yoon and $\mathrm{Kim}^{14}$ showed that marital status was associated with depressive symptoms related to job stress in nurses and explained that marriage affords greater emotional and social support. Also, younger age was a significant risk factor for a high KOSS score, and having a hobby and undertaking regular exercise reduced the KOSS score in a study of occupational stress in Korean surgeons. ${ }^{15}$ Therefore, it is difficult to conclude that the higher job stress scores of nurses compared to doctors were simply due to their job position. Likewise, whether endoscopic workers really experienced lower levels of stress than the general Korean population is questionable, considering significant differences in the sizes of the study populations (12,631 vs. 59) and the confounding effects of differences in demographic factors. Indeed, in a United States study which compared 6,179 physicians with 3,442 working adults, physicians were more likely to experience burnout (37.9\% vs. $27.8 \%)$ and to be unsatisfied with their work-life balance ( $40.2 \%$ vs. $23.2 \%)$ than the general population. ${ }^{5}$ Therefore, to identify job stress according to job position or type of occupation, further studies that adjust for demographic or lifestyle characteristics with large samples will be needed.

A previous meta-analysis showed that interventions including psychoeducation, interpersonal communication, and mindfulness meditation significantly decreased burnout in physicians. ${ }^{16}$ Taft et al. ${ }^{17}$ reported that the use of problem-focused coping strategies tended to reduce burnout and psychological distress, and increase job-related self-efficacy in GEs, although statistical significance was not reached. In addition to the stress management interventions mentioned above, several stressors identified in the present study suggest important clues to controlling job stress. Job demand, as the common stress factor for all endoscopy unit workers, is associated with the low cost of endoscopy procedures, biennial surveillance of upper gastrointestinal endoscopy, and the complex and overwhelming workload due to the growing use of interventional endoscopy, especially in Korea. Thus, organizational and societal interventions by policy makers and health care organizations are necessary to control job stress or burnout. Additionally, to correct problems related to insufficient job control, organizational systems, and a lack of recognition of nurses, employers need to provide nurses with sufficient recognition and opportunities for job promotion, better work environments, accurate communication, and increased job security. Finally, reconciliation between individual-level and workplace interventions is warranted to reduce stress and burnout in endoscopy unit workers.

\section{Conflicts of Interest}

The authors have no financial conflicts of interest.

\section{REFERENCES}

1. Wallace JE, Lemaire JB, Ghali WA. Physician wellness: a missing quality indicator. Lancet 2009;374:1714-1721.

2. Shanafelt TD, Boone S, Tan L, et al. Burnout and satisfaction with worklife balance among US physicians relative to the general US population. Arch Intern Med 2012;172:1377-1385.

3. Bragard I, Dupuis G, Fleet R. Quality of work life, burnout, and stress in emergency department physicians: a qualitative review. Eur J Emerg Med 2015;22:227-234.

4. Guveli H, Anuk D, Oflaz S, et al. Oncology staff: burnout, job satisfaction and coping with stress. Psychooncology 2015;24:926-931.

5. Dimou FM, Eckelbarger D, Riall TS. Surgeon burnout: a systematic review. J Am Coll Surg 2016 Mar 25 [Epub]. http://dx.doi.org/10.1016/ j.jamcollsurg.2016.03.022.

6. Dyrbye LN, Massie FS Jr, Eacker A, et al. Relationship between burnout and professional conduct and attitudes among US medical students. JAMA 2010;304:1173-1180.

7. Shanafelt T, Sloan J, Satele D, Balch C. Why do surgeons consider leaving practice? J Am Coll Surg 2011;212:421-422.

8. Balch CM, Shanafelt TD, Sloan JA, Satele DV, Freischlag JA. Distress and career satisfaction among 14 surgical specialties, comparing academic and private practice settings. Ann Surg 2011;254:558-568.

9. Bittner JG 4th, Khan Z, Babu M, Hamed O. Stress, burnout, and maladaptive coping: strategies for surgeon well-being. Bull Am Coll Surg 2011;96:17-22.

10. Shanafelt TD, Balch CM, Bechamps G, et al. Burnout and medical errors among American surgeons. Ann Surg 2010;251:995-1000.

11. Keswani RN, Taft TH, Coté GA, Keefer L. Increased levels of stress and burnout are related to decreased physician experience and to interventional gastroenterology career choice: findings from a US survey of endoscopists. Am J Gastroenterol 2011;106:1734-1740.

12. Son SS, Yang SJ. Job stress and job satisfaction among nurses in gastrointestinal endoscopy units. J Korean Clin Nurs Res 2014;20:189-199.

13. Nam SJ, Chun HJ, Moon JS, et al. Job stress and job satisfaction among health-care workers of endoscopy units in Korea. Clin Endosc 2016;49:266-272.

14. Yoon SL, Kim JH. Job-related stress, emotional labor, and depressive symptoms among Korean nurses. J Nurs Scholarsh 2013;45:169-176.

15. Kang SH, Boo YJ, Lee JS, Han HJ, Jung CW, Kim CS. High occupational stress and low career satisfaction of Korean surgeons. J Korean Med Sci 
2015;30:133-139.

16. Regehr C, Glancy D, Pitts A, LeBlanc VR. Interventions to reduce the consequences of stress in physicians: a review and meta-analysis. J Nerv Ment Dis 2014;202:353-359.
17. Taft TH, Keefer L, Keswani RN. Friends, alcohol, and a higher power: an analysis of adaptive and maladaptive coping strategies among gastroenterologists. J Clin Gastroenterol 2011;45:e76-e81. 